\title{
Benefits and Risks of Disclosing Human Immunodeficiency Virus Diagnosis to Perinatally Infected Children: A Critical Review of the Literature
}

Chrissie Phiri and Evelyn Chilemba*

University of Malawi, Kamuzu College of Nursing, Lilongwe, Malawi

*Corresponding author: Evelyn Chilemba, University of Malawi, Kamuzu College of Nursing, Lilongwe, Malawi, E-mail: evelynchilemba@kcn.unima.mw

Received date: Mar 27, 2015, Accepted date: May 12, 2015, Published date: May 20, 2015

Copyright: $\odot 2015$ Chilemba $E$ et al. This is an open-access article distributed under the terms of the Creative Commons Attribution License, which permits unrestricted use, distribution, and reproduction in any medium, provided the original author and source are credited.

\begin{abstract}
Disclosure of HIV infection to perinatally infected children is a contemporary issue that demands conscientiousness among health workers in dealing with those affected. This is because of the complicated treatment regimen that prompts questions from the affected children, their parents and of course the caregivers. The aim of the review was to seek evidence from literature regarding the benefits and risks of disclosing HIV status to perinatally infected children in order to influence practice in educating, informing and supporting parents/caregivers in Malawi.
\end{abstract}

The review sought for evidence in order to appreciate the benefits and risks through a critical appraisal of literature and synthesis of the findings of the existing studies. The search strategy was achieved through an electronic data base search of research articles from Medline, Embase and CINAHL. The search strategy was limited to articles published between 1996 to June 2011. These were qualitative studies conducted in Southern Africa and were in English language with relevance as the guiding principle in the search.

The review results exposes that parents of HIV infected children experience barriers to disclosure and that stigma is such a major and one of barriers to disclosure and that stigma particularly brings fear among the parents of the children. The fears came about because the children would request to know how they got infected and these type of questions would make parents upset. Therefore, it is postulated that adequate preparation and specific plans of disclosure should be designed before disclosure is implemented. The plan considers issues of age, intellectual abilities and developmental milestones. The ethical issues in giving wrong information, thus the inaccurate diagnosis when the child asked questions regarding their status are dangerous to the child's compliance to treatment regimen. Despite the secrecy surrounding the affected children's status, these children ultimately become aware of their problems.

In conclusion, some parents of the HIV affected children prefer disclosure of HIVIAIDS status to their children based on age, while others prefer giving them inaccurate diagnosis. It is envisaged that these parents need support to this dilemma from health workers. Support and discussions at convenient times with parents should be considered a major need in the management of HIVIAIDS.

\section{Introduction}

Disclosure of HIV infection to perinatally infected children is a controversial issue when children are growing which health care workers and parents have to deal with diligently. This is because the reaction of the child upon learning his/her diagnosis is unpredictable. Furthermore, parents fear that the child may not keep it a secret, since the child's diagnosis is also a reflection of their sero-status. Previously a baby born with HIV infection was regarded as having a terminal illness, a disease from which there is no recovery. This is no longer the case; the availability of antiretroviral therapy (ART) has changed HIV infection from being a terminal illness to a chronic illness, a situation which needs psychological adjustments especially in children and adolescents [1]. Perinatally HIV infected children are now growing into adolescence. According to Ledlie [2] these children are starting to live longer and enjoy a better quality of life due to early combination therapy and increasing knowledge base of HIV care. However, this has brought new challenges to parents and health care providers. Ledlie [2] highlights that as children get older, they begin to ask inescapable questions; for example; "Why do I take medicines?" Kippenberg [3] concurs and states that a five year old HIV positive child in Kenya asked her mother why she was taking medication when her siblings were not. The complicated treatment regimen prompts questions from children and consequently, parents and caregivers have to learn to answer their questions and make decisions regarding the right time to disclose the diagnosis to them [2]

As a child grows to adolescence, he/she moves from dependence to independence stage. Every age and stage of his/her development has specific goals and tasks to be achieved. The child needs many skills to successfully achieve his/her goal of increased independence. It is believed that starting early is the best way for parents to prepare for their child's adolescence. Some of the ways that parents can prepare their child for a smooth transition and greater success include; creating an atmosphere of honesty, mutual trust and respect, allowing age appropriate independence and assertiveness, developing a relationship that encourages their child to talk and teaching responsibility for his/her belongings and life [4]. 
This seems to suggest that as perinatally HIV infected children grow to adolescence and move from dependence to independence, they have an added task of managing their medical condition. As such, parents need to start early to prepare for a smooth transition by being honest, talking and teaching him/her responsibility for his/her health. It is important that parents assist their perinatally HIV infected child to take age appropriate responsibility for his/her condition from an early age, for example the child should understand the need for taking medication daily and learn to do so without persuasion from his/her parents, preventing him/herself from re-infection and transmitting the infection to others, avoiding risky behaviour like drinking alcohol and smoking, eating the right food and attending ART clinic appointments even when not feeling ill.

\section{Background}

Sub-Saharan Africa has the highest number of HIV and AIDS cases than any other region of the world. It is estimated that over twentytwo million people are living with HIV in the region, which is around two-thirds of the global total. In 2009, more than a million people died from AIDS in Sub-Saharan Africa and more than one million became infected with HIV [5]. The report further states that Sub-Saharan Africa has more HIV positive women than men. According to the report, more than two million children were living with HIV in 2009. In 2010 the number reduced to more than one million. The primary mode of transmission is through heterosexual intercourse, which accounts for eighty per cent of the infections and eight per cent is thought to be from mother to child [6]. According to UNIAIDS, 2008 cited in AVERT [5] the prevalence rate of HIV infection is higher among women than men as sixty per cent of adults living with HIV in Malawi are women and the majority of these infections occur amongst young people between 13 and 24 years of age. The prevalence rate in adults aged 15 to 49 is high. Of these more than thirteen per cent are female adults [5].

HIV screening tests done at antenatal clinics in 2009 revealed that fifty-eight per cent of pregnant women in Malawi were HIV positive [5]. This exposes the unborn child to HIV infection because only twenty-four per cent of HIV positive pregnant women attending antenatal clinics receive anti-retroviral prophylaxis (ART) to prevent transmission of the virus to their baby [5]. The transmission rate of HIV from mother to child is fifteen to thirty per cent during pregnancy and delivery and five to forty per cent through breast feeding [6]. The transmission risk through breast feeding varies depending on the duration and methods [7]. For Malawi, it is likely that the risk of transmission through breast milk is high because breast feeding is the main method of infant feeding used by women and it is the only method for rural women. This leads to many children acquiring HIV. In developing countries, 590,000 children acquire HIV type one from their mothers [8]. In Malawi, it is estimated that 120,000 children were living with HIV in 2009 [5].

Since there is little empirical evidence about disclosure of HIV diagnosis in perinatally infected children, empirical evidence about disclosure of terminal illnesses such as cancer and leukaemia has been used to examine issues that concern parents and health care professionals regarding disclosure of HIV diagnosis in children. There is evidence indicating that disclosing sensitive information to children is an issue of concern between parents and health care workers. In a study by Young et al. [9] which investigated parent's experiences of their children's presence in discussions with physicians about leukaemia, parents had different feelings regarding the presence of affected children during discussions of the illness with the physician. Findings further revealed that some parents felt that the presence of the child had important psychological benefits and showed respect for the child. Parents also felt uncomfortable withholding information from their child and viewed it as useless since the child became to know of what was going on over time. Parents, who were against the idea, felt that having discussions of the child's illness with the physician in the presence of the child would leave the child frightened and confused. Parents reported being distracted by their child's presence and viewed the physician's emotional tone and the content of the information as a threat to their child; indeed, some worried about breaking down in the presence of their child.

Similar findings were reported by Blake et al. [10] in their study "Daddy ran out of tadpoles": how parents tell their children they are donor conceived, and what their 7-year-olds understand." Findings revealed that when exploring disclosure of donor conception and what children understand, parents reported disclosure to be painful and difficult. Parents expressed concern over the age of the child, how they would explain the circumstances of conception to their child, possible questions their child would ask in the future and fear of being rejected by their child. However, after disclosure, parents expressed feeling relieved and positive about the disclosure without any adverse effects to their child.

Apparently, such fears are not limited to parents only; health care workers also experience similar difficulties during disclosure of chronic or terminal illness to families. According to Johnston and Appleby [11], paediatric oncologists in their study admitted to have some anxiety to families before disclosing bad news to families and patients. Oncologists worried about how the family would react to the disclosure, whether the family would ask about the prognosis and their lack of answers to questions that the family would ask. Some paediatric oncologists felt that the child should not be present during disclosure of the illness, while others felt the child should be present. These fears are similar to parents' feelings in the study by Young et al [9] as discussed earlier.

Disclosure of HIV status to perinatally infected children poses similar challenges. Davis and Shah [12] argue that the situation is easier in childhood cancer because communication about diagnosis is now generally considered to have a positive effect. Based on this, one reason why disclosure seems to be a controversial issue in paediatric HIV and AIDS may be because there have not been many studies carried out regarding disclosure of HIV status to perinatally infected children [13]. Another reason may be because HIV was previously regarded as a terminal illness but with the availability of ART has dramatically changed it to a long term illness; this has necessitated disclosure which was not deemed necessary before [1]. As a result, parents as well as health care professionals may not be adequately prepared to deal with it effectively. In Malawi, the HIV and AIDS National Policy states that people with HIV and AIDS should be aware of and take responsibility for protecting themselves from re-infection and protecting others from infection [14]. This policy includes young people.

The AAP [15] advocy that: "Disclosure of HIV infection status to children and adolescents should be done taking into consideration the age, psychosocial maturity, the complexity of family dynamics and the clinical context" (p.164).

The AAP [15] recognize that in most cases young children are given simple explanations about the nature of their illness and what their 
Page 3 of 9

responsibilities are regarding self-care. However, they argue that the exact diagnosis and prognosis of the disease are of less importance in early discussions with young children. This concurs with Davis and Shah [12] who acknowledges that a child can learn a lot about an illness without necessarily knowing its name. In agreement with this, Geoffrey and Weinberg [16] recommend holding disclosure discussions with school-aged children who do not have cognitive defects. However, they further highlight that much as disclosure should remain truthful, for young children, it may be partial. According to Weiner et al [17] partial disclosure is the term used to describe situations where children are not given all information about their illness. They further highlight that a child may be told of the necessity to take medication to relieve the illness without mentioning the name of the virus or disease. This may be an effective approach to use to assist parents who are not ready to use the term HIV. This is when a child is told the name of the virus, illness, disease specific information for example, how the HIV works, how it is transmitted and how he/she acquired the infection [17]. Disclosure of HIV infection to a child is important since it may create an opportunity for discussions with parents and health care professionals hence preparing him/her for self-care. According to Geoffrey and Weinberg [16], a child's knowledge of his/her HIV infection improves behaviour, social functioning and adherence to medication.

This may imply self-care as perinatally HIV infected children grow up, they have additional health-care demands; namely: seeking and getting medical care, being aware of and attending to the effects of the HIV infection, taking prescribed medications effectively, accepting themselves as being in a different state of health, learning to live with the HIV infection, preventing themselves from re-infection and infecting others. HIV positive children may not be able to perform these additional health-care demands if their illness is not disclosed to them.

The number of HIV/ AIDS cases in Sub-Saharan Africa is high. The same applies to Malawi with more women in child bearing age being infected than men. This has led to many children acquiring the infection from their mothers perinatally. Fortunately, the introduction of ART has led to these children being able to survive into adolescence; however, this has brought the challenge of parents and caregivers having to answer questions from the infected children. As a result disclosure has become a controversial issue. The purpose of the review was to find the benefits and risks of disclosure of HIV status to perinatally infected children.

The aim of this review is to find evidence from the literature regarding the benefits and risks of disclosure of HIV status to perinatally infected children in order to influence practice in educating, informing and supporting parents/ caregivers caring for HIV positive children in Malawi.

The objectives of the review encompassed the following:

- To carry out a comprehensive, systematic and in-depth search of available literature and identify studies relating to disclosure of HIV status to perinatally infected children.

- To explore current models of disclosure of HIV infection to perinatally infected children.

- To discuss the implications of evidence obtained from the review for best practice in educating, informing and supporting parents/ caregivers of HIV positive children in Malawi.

\section{Methods}

\section{The Review Process}

The aim of this review was to search for evidence in order to appreciate the benefits and risks of disclosing the HIV status to perinatally infected children. This was accomplished by a critical appraisal and synthesis of findings of existing studies. It is our expectation that this literature review will generate knowledge and increase understanding about disclosure of HIV status to perinatally infected children as they grow up.

\section{Search strategy}

The following electronic data bases were used to identify the articles in Medline, Embase and CINAHL. New leads were identified from references of the relevant articles. Search strategy was limited to articles published from June 1996 to June 2011. Qualitative studies conducted in Southern Africa and in English language were searched for relevance.

The following search terms were used during the search: HIV, AIDS, disclosure, truth telling/ interpersonal communication, child $0-18$ years and Sub-Saharan Africa.

\section{Screening and papers selection criteria}

The first screening of articles was based on titles, this was followed by screening based on abstracts and finally full texts were assessed for relevance and appropriateness. Each study was subjected to ten Critical Appraisal Skills Programme (CASP) screening questions.

The following criteria were used to exclude ineligible articles:

\section{Screen questions:}

- Was there a clear statement of the aims of the research?

- Is a qualitative methodology appropriate?

- Was the research design appropriate to address the aims of the research?

- Was the recruitment strategy appropriate to the aims of the research?

- Were the data collected in a way that addressed the research issue?

- Has the relationship between researcher and participants been adequately considered?

- Have ethical issues been taken into consideration?

- Was the data analysis sufficiently rigorous?

- Is there a clear statement of findings?

- How valuable is the research?

\section{Data extraction}

Data was extracted from the full texts. The extracted information consist of authors name, year of publication, level of knowledge, research question, purpose and study objectives, study design, study populations, study setting, number and type of participants, methods of data collection, type of intervention and study results, strengths and weaknesses. The following themes were generated from the data extraction:

- Predictors to disclosure

- Reasons for disclosure 
Citation: Chilemba E, Phiri C (2015) Benefits and Risks of Disclosing Human Immunodeficiency Virus Diagnosis to Perinatally Infected Children: A Critical Review of the Literature. J Nurs Care 4: 260. doi:10.4172/2167-1168.1000260

Page 4 of 9

- Barriers or fears related to disclosure

- Preparation for disclosure

- Outcomes of disclosure

- Inaccurate diagnosis

- Responsibility to disclose

\section{Results}

\section{Search flow}

A total number of 33 potential primary articles were identified, retrieved, documented and kept for future assessment, 25 articles had abstracts, and the rest were full texts. 25 abstracts and 8 full texts of the retrieved studies were screened for relevance and appropriateness. After reading the abstracts, 15 studies were discarded. References of 18 relevant studies were searched for new leads to more potential studies. Five studies were identified and documented, abstracts were read, two inappropriate studies were discarded, and three relevant and appropriate studies were saved [18]. 21 relevant studies were kept and full texts were read for appropriateness, 11 studies were discarded and ten studies were identified and saved for assessment. Details related to the search flow are displayed in Figure 1 below (Figure 1).

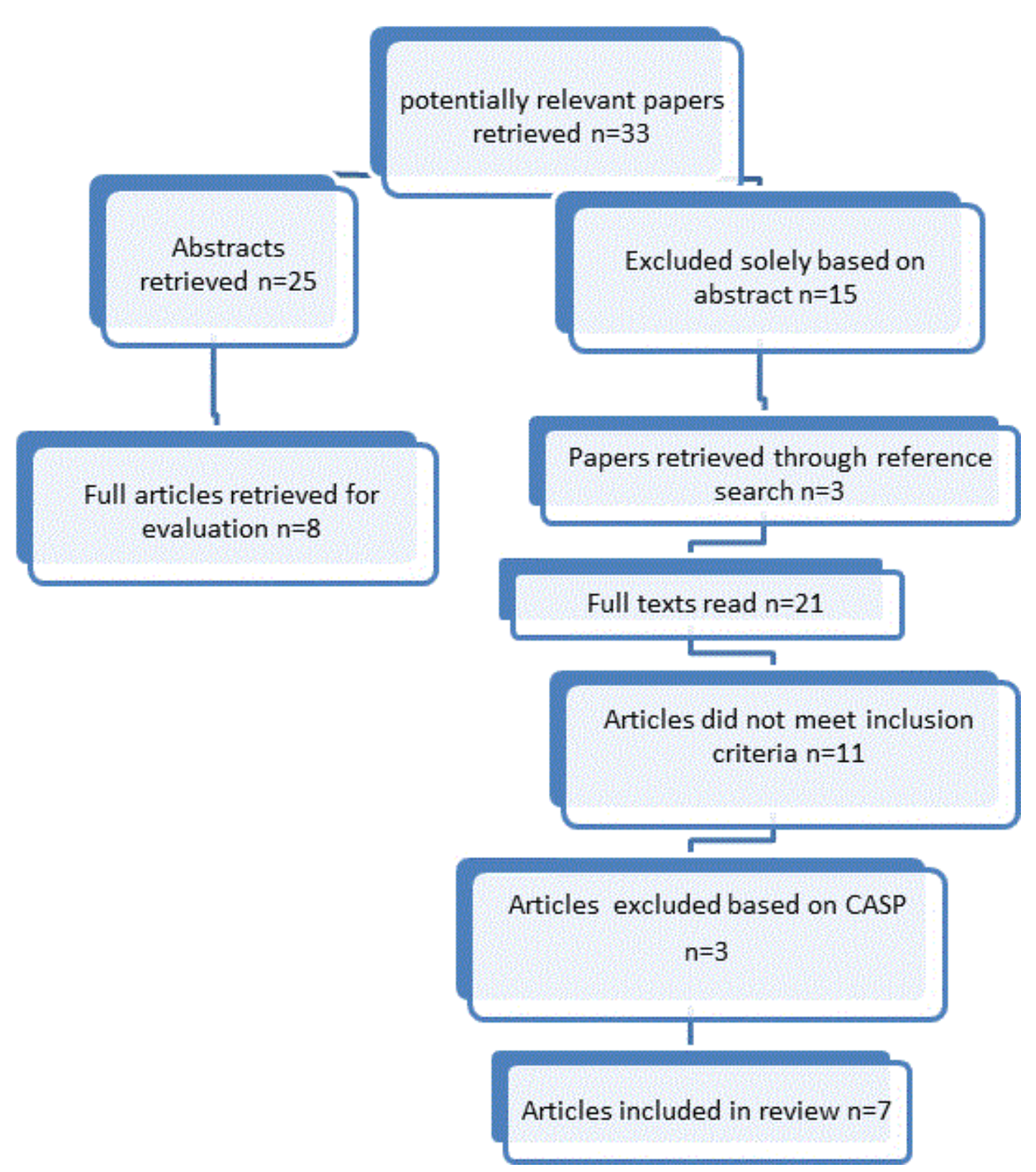

Figure 1: Search flow Adapted from Haneline and Meeker [19]. 
The seven studies were assessed for quality by examining appropriateness of methods used, study participants, sample sizes, study setting, and data collection methods, presentation of results as well as strengths and weaknesses. A methodological matrix was developed from the studies for easy comparison of studies focusing on similar themes and issues. This was followed by development of a theme matrix. The extracted data was then analyzed, integration of information and search of themes was done followed by interpretation and synthesis of themes which were discussed qualitatively in the review [20].

\section{Concepts and definitions}

In this review parent is defined as one, who begets, gives birth to, nurtures and raises a child; father or mother. While as guardian refers to one, who looks after, protects, defends. Child is defined as anyone below 18 years of birth.

\section{Benefits and risks of disclosure of HIV diagnosis to perinatally infected children}

In this review, seven themes were associated with disclosure of HIV diagnosis to perinatally infected children:

\section{Predictors to disclosure}

Four studies reported four disclosure predictors that emerged from data analysis. In Addis Ababa, Ethiopia Biadglign et al [21] and in South Africa Moodley et al [22] observed that children who were perceived to know their caregivers' health problem were more likely to be disclosed of their HIV status than those who were not. A child's age is a disclosure predictor that featured in all the four studies. In the United Kingdom, Waugh [23] reported that parents indicated that they wanted assurance that the child was old enough to realize the importance of not disclosing to other people. Biadgilign et al. [21] indicate that children whose parents have education at or above primary level have less chances of being disclosed of their HIV infection. Another disclosure predictor was the level of referral for HIV screening. Biadgilign et al. [21] indicated that children referred from hospitals and private practitioners were more likely to be informed of their illness than those from community

\section{Reasons for disclosure}

Four studies explored reasons for disclosure from parents. Moodley et al. [22] report that parents indicated that the child has the right to know about his/her illness, availability of ART and their concern for the child's mental status made it necessary to disclose to their child of the illness. Vaz et al. [13] indicate that parents were compelled to disclose the HIV diagnosis to their child due to the child's refusal to take ART, availability of ART, worsening of illness, fear of child infecting siblings and other people and child's increase in age. Vreeman et al. [24] suggest that parents reported that they disclosed the HIV diagnosis to their children to enhance adherence to ART. Lastly, Waugh [24] reports the child's right to information, fear of infecting others and helping the child make decisions about medications as parents' reasons for disclosure of illness to their child.

\section{Barriers to disclosure}

A study in Uganda revealed that parents feared that if their child knew of his/her HIV infection he/she would tell other people and the child would be stigmatized at school [25]. In Soweto, South Africa, Kouyoumdjian et al. [25] reports that parents indicated discrimination, being judged as promiscuous, social rejection, isolation, being associated with gay disease, parent's lack of knowledge of HIV and AIDS and disclosure being emotionally and psychologically challenging as barriers to disclosure. According Moodley et al. [22] findings in South Africa indicate those parents feared that the child would discuss his/her infection with other people. In Kenya, Vreeman et al. [26] report that parents reported fear of negative psychological consequences after disclosure and the possibility of the child disclosing to other people. Lastly in the United Kingdom, Waugh [24] reports that parents feared discrimination, stigmatization and that the child would want to how he/she got infected which would lead to upset, hatred, committing suicide and worrying about mum dying.

\section{Preparation for disclosure}

A study conducted in Kinshasa, Democratic Republic of Congo, Vaz et al. [14] report that parents prepared the child's favourite meal, offered the child gifts, made the child feel loved, talked to the health care worker, planned answers to their child's questions in advance and some conducted prayers in preparation for disclosure of HIV diagnosis to their child.

\section{Outcomes of disclosure}

In Addis Ababa, Ethiopia, Biadgilin et al. reported that children reported being discriminated and stigmatized after disclosure [21]. In Uganda Bikaako-Kajura et al. [26] indicate that parents observed that the child had increased adherence to medication after learning about his/her infection, there was supportive and trusting relationship with parents and the child sought ways of dealing with stigma as opposed to situations where parents had to force or bribe the child to take his/her medications for those who did not disclose the illness to their child. Vaz et al. [14] reports that children in Kinshasa, Democratic Republic of Congo, reported that they felt sad and worried about stigma. Children asked about source of the infection, getting better or cured and AIDS being fatal. However, other children expressed relief; felt it is necessary and important to know as they would not worry anymore and expressed that knowledge helps to avoid being more sick and enabling to protect others.

\section{Inaccurate diagnosis}

Biadgilign et al. [21] reported that parents in Addis Ababa, Ethiopia, preferred to tell their child that he/she had tuberculosis, heart failure. In Soweto, South Africa, Kouyoumdjian [25] reported that parents told their she/he had inoperable spleen condition. In Kinshasa, Democratic Republic of Congo, Vaz et al. [13] reported that parents told their child that he/she had chest or stomach problem, while as in the United Kingdom; parents told their child that hospital visits were necessary to stop the infections.

\section{Responsible person for disclosure}

In Addis Ababa, Ethiopia, parents reported that doctors were responsible for disclosing the illness to their child because of their knowledge [21]. Kouyoumdjian et al. [25] reported that parents in Soweto, South Africa suggested parents, social workers, other family member and media were responsible for disclosing the illness to their child. In South Africa, parents and health care provider were indicated 
as responsible to disclose to the child [22]. This concurs with, Vaz et al.[13] in Kinshasa, Democratic Republic of Congo. According to Waugh [23] in the United Kingdom, parents depict that they were responsible for disclosure, in conjunction with a doctor, books and media.

\section{Discussion}

The aim of this critical review of literature was to explore the benefits and risks of HIV diagnosis disclosure to perinatally infected children from studies conducted in Southern Africa. Seven studies were reviewed, six of them were carried out in African countries and one study took place in the United Kingdom, it was included because of its relevance for the review [20]. Findings revealed that limited research has been carried out on disclosure of HIV diagnosis to perinatally infected children. The few studies findings indicate that parents have different opinions regarding this issue.

Several similarities and differences in findings were observed among the studies eligible for the review. The first theme, predictors to disclosure, emerged from the study by Biadgilign et al. [21] and was common to three other studies in the review. The disclosure predictors included the child's age, child's knowledge of parent's health problem, level of referral and parent's level of education. It is possible that educated parents may not want to be associated with the disease because they consider themselves "better" than those with a low education. Sheik and Gray [27] indicate that parents from rural settings are less likely to disclose HIV diagnosis to their child than parents from urban settings because, parents from rural settings lack HIV education and services, so negative attitudes about HIV are prevalent. This seems to contradict with Biadgilign et al's [21] findings. But, it concurs with Kouyoumdjian et al's [25] findings which indicate that parents from Soweto, a rural setting in South Africa, acknowledged that their lack of knowledge regarding HIV was a barrier to disclosure of HIV diagnosis to their children. It may be necessary to explore this further.

The review established that the age of the child is the strongest disclosure predictor with very few children less than seven years of age knowing their HIV status. However, disclosure rates vary from place to place and even from one group of people to another within the same place. For example, in South Africa, parents indicated 11 years as the best age to disclose to a child [22]. In India, a study by Bhattacharya et al. [28] revealed that the mean age at disclosure was nine. A study in South Africa by Myer et al. [29] indicated that health care providers gave the age of six as the best time to start having general discussions with a child regarding their infection stating that at this age, the child is able to understand the concept of health and disease, and they start formal schooling and interact with other children. In contrast, parents in the same study gave the age of 10 or before puberty, as the best time to commence discussions with the child about HIV/AIDS because that is when they would understand difficult concepts of chronic illness. Apparently, health care workers may not find it very difficult to discuss HIV diagnosis with a six year old child because of their experience which parents lack. Parents may fear that the child will disclose to other people [15]. Mellins et al. [30] argue that delaying disclosure up to adolescence, poses a risk of the child transmitting the infection to others since he/she may be sexually active. In support of the notion Cecere, Scicchitano, Zito, Sassara et al. [31] are of the view that multi-specialised team approach around the patient improves control of disease as the approach allows the possibility of individualized therapy based on clients' real clinical condition.
Arun [32] suggests that the best time for HIV infected children to be disclosed of their infection is from nine-ten years or older because, according to the theory of child's cognitive understanding of illness, it is considered that this is when they are more likely to understand the causes of their illness and its consequences. Unfortunately, this statement is general; it does not take into account some differences. Every child is different; some children may not be ready for disclosure at age nine -ten and to some this may be late. For example, Kippenberg [3] reported that a five year old child in Kenya asked her mother why she was taking medication daily when her siblings were not. This seems to suggest that this girl was ready for disclosure four years earlier than the age recommended by Arun.

The American Academy of Paediatrics [15] recommends that disclosure discussions should be held with school aged children if they do not have cognitive defects. Likewise, children in different parts of the world start school at different ages, school age is not universal. Sheik and Gray [27] argue that a child's developmental readiness to understand the nature of HIV diagnosis and prognosis, determines whether disclosure to him/her takes place early or not.

Apparently, disclosure of HIV diagnosis also varies from one ethnic group to another due to cultural attitudes about HIV disease. For example, according to Mellins et al. [30], Latinos tend to be more secretive about sexual and drug risk behaviours which contribute to HIV transmission, and so they may not discuss HIV diagnosis with their child. Similarly, in the Malawian context, culturally, parents/ adults tend to be secretive about sexual issues and discussing HIV with their child may be a challenge. However, Close [1] highlights that healthcare professional's play a big role in assisting parents with disclosure process.

Based on this, it might be argued that it is difficult to prescribe the specific age when disclosure of the child's HIV diagnosis should begin because every child is different. It may be concluded that the child is the best determinant of this and parents should respond to the child's needs accordingly. When the child starts to ask questions, it signifies that he/she is ready for discussions and parents should offer age appropriate information at that time, however, they may require help to do so.

Four studies in the review explored reasons for disclosure from parents. Findings indicated that parents had various reasons for disclosure of HIV diagnosis to their children. Moodley et al. [22] reported that parents felt that the child had a right to know his/her condition, while some gave reasons related to the child's mental wellbeing and the availability of ART as reasons for disclosure. Furthermore, Vaz et al.[13] reported that some parents mentioned the child's refusal to take medications, the child's increase in age, deterioration of child's health and to enable the child to make decisions regarding his/her medications and taking precautions to prevent infecting other people. Weiner et al's [17] study reported similar findings; that parents felt that their child had a right to know his/her health status, they feared that the child would engage in sexual activities without protection and hoped that the child's knowledge of their HIV infection, would lead to more adherence to medication and improved health care. Kippenberg [3] concurs with this and reports that many adolescents start having sex before learning about their status and risk re-infection and spreading the virus to other people.

The Convention on the Rights of a child stipulates that children below 18 have the right to health information [33]. Likewise, the AAP [15] recommends disclosure of HIV infection to children and 
adolescents. In Malawi, the Malawi HIV and AIDS National Policy states that people with HIV and AIDS should be aware of and take responsibility for protecting themselves from re-infection and protecting others from infection [14]. This suggests that disclosure of HIV infection to children is considered important.

However, the studies also indicated that there were some parents who were against disclosure. Parents explained that disclosure might cause negative psychological consequences for the child, parents felt the child would be "having thoughts, thinking and thinking" and refuse to play with other children [24]. Similar findings were reported by Waugh [23], parents worried that the child would be upset about having HIV that they might suffer and die or might withdraw from society then commit suicide. This is worrisome because such children may reach adolescence without being disclosed of their illness and they might engage in risky behaviours resulting in re-infection and further transmission of the virus. It is important to realise that, it may not be possible to hide the HIV diagnosis for long, because as the child grows he/she may learn about the disease from the media, or from other people in a way which is traumatic. As indicated by Kippenberg [3], a girl who was not disclosed of her infection stopped taking her medications after taking them for two days, when she overhead people saying that the medications she was taking were for people with HIV and AIDS. This is an example that a child is likely to learn of his/her HIV diagnosis regardless of parents keeping the diagnosis from him/ her. In Kenya, Vreeman [24] reported that parents feared that disclosure of HIV diagnosis may be potentially harmful to children as they may not be able to handle consequences of disclosure. In view of this, we suggests that parents' reasons for resisting disclosure should be respected, furthermore, clinicians should explore the factors associated with the resistance and help parents to work on them.

The review revealed that parents expressed barriers to disclosure. Bikaako-Kajura et al. [26] and Waugh [23] reported that stigma was one barrier. Kouyoumdjian et al. [26] indicates that fear of discrimination, being judged as promiscuous, social rejection, isolation, being associated with gay disease, inadequate knowledge about HIV and finding disclosure psychologically and emotionally challenging are barriers to disclosure. Furthermore, Waugh [23] reported that parents feared that their child would know how he/she got infected and would get upset and hate them. This seems to suggest that stigma was the main barrier to parents' disclosure of HIV diagnosis to their child.

According to Close [1], stigma surrounding HIV started with the association of the infection with homosexual men and intravenous drug users. The media started to refer to HIV as the "gay plague" which led to people associating HIV with immoral behaviour such as sexual promiscuity and intravenous drug abuse. Considering the circumstances through which HIV is transmitted to a child, parents may fear that their child would perceive them as immoral. Stigma leads to an environment of secrecy in a family; unfortunately, the child senses the secrecy through observing how parents interact with other people and how they discuss or avoid discussing the topic in his/her presence and becomes aware of parents' feelings towards his/her illness and this increases stigma. Therefore, we suggest that educating communities, parents and children infected with and affected by HIV and AIDS may be of importance in supporting families.

The study by Vaz et al. [13] explored how parents prepared their children for disclosure. Findings revealed that parents prepared the child's favourite food, bought gifts, made the child feel loved, prayed, talked to a doctor and some planned answers to anticipated questions.
This suggests that parents felt that considering the nature of the infection and the circumstances under which a child contracts it, preparation for disclosure is necessary. The American Academy of Paediatrics [15] suggest that disclosure should be planned and discussed between parents and healthcare professionals and may require a number of visits to the clinic to assess the child's knowledge and ability to cope.

Human Rights Watch [34] suggest that parents and a health care professional should make a disclosure plan taking into consideration:

- Child's age, intellectual ability and developmental understanding of HIV and prognosis.

- What the child has already been told.

- What he/she knows about medication and hospital visits?

- Child's health.

- Other disclosures for example, parent's HIV diagnosis.

- Parent's thoughts about disclosure.

- Cultural influences.

- Family social circumstances.

- Child's anticipated response.

- Type of support available to child and parents after disclosure.

Furthermore, it is suggested that the child should be assessed on his/her school performance, family and peer relationships and support, interests, activities, mood and behaviour pre and post disclosure. Likewise, Sheik and Gray [27] suggest that disclosure of HIV diagnosis to a child should be planned and done in a loving and reassuring manner. This shows that disclosure of HIV diagnosis to a child is not a "one off" event and requires special preparation rather than merely giving gifts or favourite food to a child.

Parents reported various outcomes regarding their decision to, or not to disclose the HIV diagnosis to their child. Biadgilign et al. [21] reported that parents who disclose the HIV diagnosis to their children reported being discriminated and stigmatized. Bikaako-Kajura et al. [26] indicated that parents who reported the child's adherence to medications had supportive and trusting parent-child relationship and the child's ability to seek ways to deal with stigma. In contrast, those who did not disclose to their child reported having to force or bribe their child to take medication. Furthermore, Vaz et al. [13] indicated that children who were told of their HIV diagnosis reported that it was important for them to know since it helped them to stop worrying and be able to protect others. Likewise, the Human Rights Watch [34] indicates that older adolescents, who are aware of their HIV diagnosis, can choose to use protection during sex and other risky behaviours, are able to participate more actively in the treatment and are more likely to adhere to ART, learn about their infection in a supportive way making them to be more self -confident and they learn that it is acceptable to talk about HIV, helping them to address stigma associated with the infection.

We strongly suggest that disclosure can be beneficial and may reduce harm by reducing anxiety and facilitate addressing worries, because fear of unknown can be greater than fear of a known illness. Besides, disclosure may facilitate psychotherapy, since HIV can be discussed openly and directly, and, a child's knowledge of his/her infection may enable him/her to cope with the disease and possible fears of death from HIV. Sheik and Gray [27] emphasize that disclosure enables parents and their child to cope and support each other, increases intimacy between parents and their child hence strengthening family ties, relieves parents of the burden of keeping 
secret and anxiety of possibility of accidental disclosure, forms an essential part of good health, indicates parents' respect of their child regarding his/her rights, empowers the child to participate in their health care which increases hope and enables choices regarding selfprotection. In contrast, Ayebale [35] indicates that nondisclosure prevents HIV infected children from getting appropriate and timely support. According to Kiltzman et al.[36] HIV infected youth who have not been disclosed of their diagnosis may experience anxiety and related emotional and behavioral problems.

We acknowledge that there are positive and negative outcomes to disclosure of HIV diagnosis to a child, but it is important to carefully examine how disclosure may benefit a child and how the negative outcomes may be worked out to help the child live as normal a life as possible within the circumstances of the condition.

Three studies in the review revealed that parents who did not disclose the HIV infection to their child told him/her an inaccurate diagnosis; for example, that they had an inoperable disease, tuberculosis or heart problem, whenever the child asked questions regarding medications or hospital visits. However, as indicated earlier, despite the secrecy, children become aware of the nature of their illness, unfortunately, sometimes this occurs in a traumatic way. This concurs with Mellins et al.[30] who report that two children knew about their HIV infected through a television HIV/AIDS programme, the children learnt that the daily medication they were taking is for people with HIV infection. Upon learning this, one of the children told her sibling: "I have AIDS or HIV but don't tell mum and dad because they don't know that I know" (p.92).

This suggests that children who are not told of their HIV infection are aware of it, and sense that they cannot discuss it with their parents openly.

Five studies in the review investigated who should disclose to the child his/her HIV diagnosis, and parents gave different responses. For example, Biadgilign et al. [21] indicated that parents preferred the doctor, family member or social worker to disclose to their child because of the experience these people have. Some parents may prefer someone to disclose to their child because they feel guilty for infecting him/her, others may fear that their HIV diagnosis will be known by the child and other people, since the child's HIV infection indicates that they too are infected. Waugh [23] indicated that some parents felt they were the right people to disclose to the child. These findings indicate that there are some parents who prefer disclosing the HIV diagnosis to their child at a certain age, while others prefer telling him/her an inaccurate diagnosis. Both groups have their reasons for doing so. However, those who prefer disclosing the HIV infection to their child also have varying recommendations regarding who should disclose to the child.

This review has strengthened knowledge regarding disclosure of HIV diagnosis to perinatally infected children. It has also shown that parents' concerns regarding disclosure of HIV diagnosis to their children, in African countries where the studies were conducted, are shared by parents in other parts of the world.

\section{Study Limitations}

This critical review of the literature is limited since only five African countries were represented, and only two studies were solely on disclosure, the rest were investigating other phenomena such as adherence to ART and disclosure was part of the contributory factors they were examining. Furthermore, there was no study from Malawi; this would have given insight into how parents view disclosure in a Malawian context.

\section{Recommendations}

Disclosure of HIV diagnosis to perinatally infected children needs to be investigated in Malawi to appreciate what parents are experiencing in this area and be able to educate, inform and support them accordingly. It is necessary to educate communities on HIV and AIDS to enable people to be confident and open to talk about the disease, this may reduce stigma and enable families who are affected and infected get support.

\section{Implications for Practice}

This critical review of the literature on the benefits and risks of disclosing HIV diagnosis to perinatally infected children provides evidence that disclosure of HIV diagnosis to infected children is a controversial issue. Therefore, it is important to support and discuss with parents, the benefits of disclosing the diagnosis to their child, fears they may have, how the fears may be dealt with, while taking into consideration the child's age and ethical implications regarding disclosure of HIV diagnosis in children.

\section{Conclusion}

This is a critical review of the literature on benefits and risks of disclosing HIV diagnosis to perinatally infected children. Its aim was to find evidence from the literature regarding the benefits and risks of disclosure of HIV status to perinatally infected children in order to educate, inform and support parents/ caregivers caring for perinatally HIV infected children in Malawi. Through a thorough search of Medline, Embase, CINAHL and references of potential review studies, 21 qualitative studies were retrieved and considered potential for the review. After reading abstracts and assessing for relevance, using CASP, seven studies were included in the review. Studies that did not meet the inclusion criteria for the review were used as support literature in the discussion. A methodological matrix was developed, seven themes; predictors, reasons for disclosure, barriers to disclosure, inaccurate diagnosis, preparation for disclosure and responsible person for disclosure, emerged from the review. The themes were interpreted, and discussed qualitatively. Similarities and differences in study findings between studies in the review were identified and discussed along with the support literature that did not meet the criteria of the review. Six themes were shared by most of the studies included in the review, only one study explored preparation for disclosure. The study was limited because of lack of studies conducted on disclosure of HIV diagnosis to children in Southern Africa. It is recommended that studies on this subject be undertaken in Malawi in order to appreciate what parents are experiencing in this area and be able to educate, inform and support them accordingly.

\section{References}

1. Close K. L. (2010) Psychosocial Aspects of HIV/AIDS: Children and Adolescents. HIV Curriculum for the Health Professional.

2. Ledlie SW (2001) The psychosocial issues of children with perinatally acquired HIV disease becoming adolescents: a growing challenge for providers. See comment in PubMed Commons below AIDS Patient Care STDS 15: 231-236. 
3. Kippenberg J. (2010) Kenya Support Disclosure of HIV status to children. Human Rights Watch.

4. [No authors listed] (1999) Disclosure of illness status to children and adolescents with HIV infection. American Academy of Pediatrics Committee on Pediatrics AIDS. See comment in PubMed Commons below Pediatrics 103: 164-166.

5. Avert (2009) HIV and AIDS Information: International HIV and AIDS charity.

6. Kemp J, Aitken J, LeGrand S, \& Mwale B (2003) Equity in Health Sector Responses to HIV/ AIDS in Malawi.Regional Network for Equity in Health in Southern Africa.

7. Bulteel N, Henderson P (2007) Evidence behind the WHO guidelines: hospital care for children: what are the risks of HIV transmission through breastfeeding? See comment in PubMed Commons below J Trop Pediatr 53: 298-302.

8. De Cock KM, Fowler MG, Mercier E, de Vincenzi I, Saba J, et al. (2000) Prevention of mother-to-child HIV transmission in resource-poor countries: translating research into policy and practice. See comment in PubMed Commons below JAMA 283: 1175-1182.

9. Young B, Ward J, Salmon P, Gravenhorst K, Hill J, et al. (2011) Parents experiences of their children's presence in discussions with physicians about Leukemia. See comment in PubMed Commons below Pediatrics 127: e1230-1238.

10. Blake L, Casey P, Readings J, Jadva V, Golombok S (2010) 'Daddy ran out of tadpoles': how parents tell their children that they are donor conceived, and what their 7-year-olds understand. See comment in PubMed Commons below Hum Reprod 25: 2527-2534.

11. Johnston DL, Appleby W (2011) Pediatric oncologists opinions on breaking bad news. See comment in PubMed Commons below Pediatr Blood Cancer 56: 506

12. Davis JK, Shah K (1997) Bioethical aspects of HIV infection in children. See comment in PubMed Commons below Clin Pediatr (Phila) 36: 573-579.

13. Vaz LM, Eng E, Maman S, Tshikandu T, Behets F (2010) Telling children they have HIV: lessons learned from findings of a qualitative study in sub-Saharan Africa. See comment in PubMed Commons below AIDS Patient Care STDS 24: 247-256.

14. Government of Malawi (2004) National HIV/ AIDS Policy A Call for Renewed Action. Office of the President and Cabinet. National AIDS Commission

15. [No authors listed] (1999) Disclosure of illness status to children and adolescents with HIV infection. American Academy of Pediatrics Committee on Pediatrics AIDS. See comment in PubMed Commons below Pediatrics 103: 164-166.

16. Geoffrey A, Weinberg M.D (2010) Disclosure of HIV to Perinatally Infected Children and Adolescents. Medscape HIV/AIDS Clinical Guidelines: NYS Department of Health AIDS Institute.

17. Wiener LS, Battles HB, Heilman N (2000) Public disclosure of a child's HIV infection: impact on children and families. See comment in PubMed Commons below AIDS Patient Care STDS 14: 485-497.

18. Hemmingway P, Brereton N (2009) Evidence-based medicine. What is a systematic review? 2nd edition $\mathrm{P} 4$.

19. Haneline M.T, Meeker W.C. (2009) Introduction to Public Health for Chiropractors 2nd edition. Mississauga, Ontario, USA.
20. Crookes P, Davies S. (1998) Research into Practice: Essential Skills for Reading and Applying Research in Nursing and Health Care 2nd edition. Elsevier Ltd, China.

21. Biadgilign S, Deribew A, Amberbir A, Escudero H.R, Deribe K (2011) Factors Associated with HIV/AIDS Diagnostic Disclosure to HIV Infected Children Receiving HAART: A Multi-Center Study in Addis Ababa, Ethiopia. PLoS One, 6: 1-6.

22. Moodley K, Myer L, Michaels D, Cotton,M (2006) Paediatric HIV disclosure in South Africa-caregivers' perspectives on discussing HIV with infected children. South African Medical Journal, 96: 200-204.

23. Waugh S (2003) Parental views on disclosure of diagnosis to their HIVpositive children. See comment in PubMed Commons below AIDS Care 15: $169-176$

24. Vreeman R.C, Nyandiko W.M, Ayaya S.O, Walumbe E.G, Marrero D.G, et al. (2010) The Perceived Impact of Disclosure of Paediatric HIV Status on Paediatric Antiretroviral Therapy Adherence, Child Well-Being, and Social Relationships in a Resource-Limited Setting. AIDS Patient Care and STDS, 24: 639-649.

25. Bikaako-Kajura W, Luyirika E, Purcell DW, Downing J, Kaharuza F, et al. (2006) Disclosure of HIV status and adherence to daily drug regimens among HIV-infected children in Uganda. See comment in PubMed Commons below AIDS Behav 10: S85-93.

26. Kouyoumdjian FG, Meyers T, Mtshizana S (2005) Barriers to disclosure to children with HIV. See comment in PubMed Commons below J Trop Pediatr 51: 285-287.

27. Sheik A.N, Gray G (2005) HIV Disclosure in Children. The Southern African Journal of HIV Medicine, 46-48.

28. Bhattacharya M, Dubey AP, Sharma M (2011) Patterns of diagnosis disclosure and its correlates in HIV-Infected North Indian children. See comment in PubMed Commons below J Trop Pediatr 57: 405-411.

29. Myer L, Moodley K, Hendricks F, Cotton M (2006) Healthcare providers' perspectives on discussing HIV status with infected children. See comment in PubMed Commons below J Trop Pediatr 52: 293-295.

30. Mellins C.A, Brackis-Cott E, Dolezal C, Richards A, Nicholas S.W, et al. (2002) Patterns of HIV Status Disclosure to Perinatally HIV-Infected Children and Subsequent Mental Health Outcomes. Clinical Child Psychology and Psychiatry 7: 101-114.

31. Cecere A, Scicchitano P, Zito A, Sassara M, Bux F, et al. (2014). Role of Care Manager in Chronic Cardiocascular Disease. Annals of Gerontology and Geriatric Research, 1: 1005

32. Arun S, Singh AK, Lodha R, Kabra SK (2009) Disclosure of the HIV infection status in children. See comment in PubMed Commons below Indian J Pediatr 76: 805-808.

33. Child Health (2000) Promoting the care and rights of children. The International Newsletter on Child Health and Disease Prevention.

34. Human Rights Watch (2005) Positively Abandoned-Stigma and Discrimination Against HIV-Positive Mothers and their Children in Russia.

35. Ayebale L. (2010) Parents must reveal children's HIV status to school teachers. New Vision, Uganda

36. Klitzman R, Marhefka S, Mellins C, Wiener L (2008) Ethical issues concerning disclosures of HIV diagnoses to perinatally infected children and adolescents. See comment in PubMed Commons below J Clin Ethics 19: $31-42$. 